\title{
Tribological behavior of layered double hydroxides with various chemical compositions and morphologies as grease additives
}

\author{
Hongdong WANG ${ }^{1}$, Yue WANG ${ }^{1,2}$, Yuhong LIU ${ }^{1, *}$, Jun ZHAO ${ }^{1,3}$, Jinjin LI $^{1}$, Qiang WANG ${ }^{4, *}$, Jianbin LUO ${ }^{1, *}$ \\ ${ }^{1}$ State Key Laboratory of Tribology, Tsinghua University, Beijing 100084, China \\ ${ }^{2}$ School of Mechanical Engineering, Guizhou University, Guiyang 550025, China \\ ${ }^{3}$ College of Mechanical and Electrical Engineering, Beijing University of Chemical Technology, Beijing 100029, China \\ ${ }^{4}$ College of Environmental Science and Engineering, Beijing Forestry University, Beijing 100083, China \\ Received: 20 September 2019 / Revised: 31 December 2019 / Accepted: 03 March 2020 \\ (C) The author(s) 2020.
}

\begin{abstract}
The layered double hydroxide (LDH) is a kind of natural mineral, which can also be manually prepared. It has been practically applied in various fields due to its unique crystal structure and diversity of composition, size, and morphology. In this work, LDHs with different chemical compositions $\left(\mathrm{Co}^{2+}, \mathrm{Mg}^{2+}, \mathrm{Zn}^{2+}\right.$, and $\mathrm{Ni}^{2+}$ ) and topographical features (flower-like, spherical, and plate-like) were successfully prepared by controlling the reaction conditions. Then, they were mechanically dispersed into base grease and their tribological properties were evaluated by a ball-on-disk tester under a contact pressure of $2.47 \mathrm{GPa}$. It was found that the variation of morphology, instead of chemical composition, had great influence on the tribological performance. The "flower-like" LDH sample with high specific surface area $\left(139 \mathrm{~m}^{2} / \mathrm{g}\right)$ was demonstrated to show the best performance. With $1 \mathrm{wt} \%$ additive, the wear volume was only about $0.2 \%$ of that lubricated by base grease. The tribofilm with unique microscopic structure and uniform composition was derived from tribochemical reaction between LDH additives and sliding solid surfaces, effectively improving tribological properties of the lubrication system. This work provided the guidance for optimizing lubricant additives and held great potential in future applications.
\end{abstract}

Keywords: layered double hydroxide; lubricant additive; tribological property; grease; graphene oxide

\section{Introduction}

Friction is quite common in our daily life and industrial activities. However, unnecessary friction and related wear may cause huge losses, specifically accounting for about $5 \%$ to $7 \%$ of their gross national product in highly industrialized countries [1-3]. In the past few years, novel lubricant materials and concepts have been constantly explored and optimized so as to avoid unnecessary friction in most industrial processes, including manufacturing, power transmission, transportation, etc. [4-6]. Among them, two-dimensional materials attracted great attention in the field of tribological research due to their unique crystal structure and physicochemical properties. As compared with ordinary nanoparticles as lubricant additives, two-dimensional materials possess smaller longitudinal dimension so that they are much easier to enter the contact area between sliding solid surfaces [7]. Typically, a large variety of layered materials such as $\mathrm{MoS}_{2}$ [7-10], black phosphorus [11, 12], and graphitederived materials [13-17], have been most widely reported because of relatively high specific surface area for good dispersion in lubricant and relatively

\footnotetext{
* Corresponding authors: Yuhong LIU, E-mail: liuyuhong@tsinghua.edu.cn; Qiang WANG, E-mail: qiangwang@bjfu.edu.cn; Jianbin LUO, E-mail: luojb@mail.tsinghua.edu.cn
} 
weak van der Waals forces for easy shear between their laminates.

Recently, a kind of layered natural mineral called layered double hydroxide (LDH), which can also be prepared by chemical synthesis means, was reported to exhibit excellent tribological properties when utilized as additives in both oil- and water-based lubricants [18-22]. The chemical formula can be expressed as: $\left[\mathrm{M}^{2+}{ }_{1-x} \mathrm{M}^{3+}{ }_{x}(\mathrm{OH})_{2}\right]^{x+}\left(\mathrm{A}^{n-}\right)_{x / n} \cdot m \mathrm{H}_{2} \mathrm{O} . \mathrm{M}^{2+}$ and $\mathrm{M}^{3+}$ are divalent and trivalent metal cations, respectively; $\mathrm{A}^{n-}$ is the interlayer anion for charge balance. Metal cations are located at the center of the hexagonal crystal of the laminates, while the hydroxide ions occupy the apexes of the hexagonal crystal. Most of metal cations, such as $\mathrm{Mg}^{2+}, \mathrm{Al}^{3+}, \mathrm{Fe}^{3+}, \mathrm{Co}^{2+}, \mathrm{Ni}^{2+}, \mathrm{Cu}^{2+}, \mathrm{Zn}^{2+}$, etc., can achieve atomic-level dispersion in the laminates of LDHs. LDH materials and their composite products have been widely reported in the field of energy storage, ion exchange, drug delivery, and flame retardant additives, etc. [23-25]. As lubricant additives, LDH nanoplatelets may facilitate the formation of a protective tribofilm with good mechanical properties during sliding process [21]; besides, ultrathin LDH nanosheets were utilized to enable the sliding solid surfaces to be polished and protected because of their relatively weak interlayer interaction [22]. Due to its diversity in terms of chemical composition, particle size, and macroscopic morphology, the practical application and mechanism analysis in the field of tribology deserve further exploration.

In this paper, as-prepared LDH products were controlled in many aspects including size, morphology (flower-like, spherical and plate-like) and chemical composition $\left(\mathrm{Co}^{2+}, \mathrm{Mg}^{2+}, \mathrm{Zn}^{2+}\right.$, and $\left.\mathrm{Ni}^{2+}\right)$ by selecting different preparation methods and adjusting reaction process. Then, they were mechanically dispersed into base grease and their tribological properties were evaluated by a ball-on-disk tester under the same experimental conditions. As comparing different features of LDH additives and observing the wear condition after friction test, the chemical composition and microstructure in contact area were analyzed. Finally, lubrication mechanism of LDHs in base grease was proposed and the guidance for selecting appropriate additives in future applications was provided.

\section{Materials and methods}

\subsection{Preparation}

A coprecipitation method was adopted to prepare the LDHs with various morphologies and chemical compositions. The morphology of LDHs can be controlled by adjusting the $\mathrm{pH}$ of solution in the crystallization state. The "flower-like" LDHs were prepared as follows: $50 \mathrm{~mL}$ aqueous solution containing $0.0375 \mathrm{~mol} \mathrm{Mg}\left(\mathrm{NO}_{3}\right)_{2}$ and $0.0125 \mathrm{~mol} \mathrm{Al}\left(\mathrm{NO}_{3}\right)_{3}$ was added dropwise to another $50 \mathrm{~mL}$ aqueous solution containing $0.025 \mathrm{~mol}$ of $\mathrm{Na}_{2} \mathrm{CO}_{3}$. At the same time, the $\mathrm{pH}$ of reaction solution was controlled at about 10 using $4 \mathrm{~mol} / \mathrm{L} \mathrm{NaOH}$ aqueous solution. The resulting mixed solution was kept under magnetic stirring at room temperature for 12 hours. The synthesis process of the LDHs sample which tends to be "spherical" was similar to the above reaction process, except that the $\mathrm{pH}$ of reaction solution maintained at about 12 . The "plate-like" LDHs sample need to crystallize in a hydrothermal reactor at $150{ }^{\circ} \mathrm{C}$ for three days after the initial solution of "spherical" sample was prepared, instead of magnetic stirring at room temperature. After three samples were prepared, they were washed with deionized water to keep the final product at $\mathrm{pH} 7$, and finally dried at $100{ }^{\circ} \mathrm{C}$ for 12 hours to obtain powder samples. A variety of LDHs with different metal divalent ions were prepared as follows: a $100 \mathrm{~mL}$ aqueous solution containing $0.05 \mathrm{~mol}$ of $\mathrm{Mg}\left(\mathrm{NO}_{3}\right)_{2}$ $\left(\mathrm{Ni}\left(\mathrm{NO}_{3}\right)_{2}, \mathrm{Co}\left(\mathrm{NO}_{3}\right)_{2}\right.$, or $\left.\mathrm{Zn}\left(\mathrm{NO}_{3}\right)_{2}\right)$ and $0.025 \mathrm{~mol}$ of $\mathrm{Al}\left(\mathrm{NO}_{3}\right)_{3}$ was prepared and added dropwise to a $100 \mathrm{~mL}$ aqueous solution containing $0.05 \mathrm{~mol}$ of $\mathrm{Na}_{2} \mathrm{CO}_{3}$. Subsequently, the $\mathrm{pH}$ was controlled at 10 using $3.4 \mathrm{~mol} / \mathrm{L} \mathrm{NaOH}$ aqueous solution. Then, the obtained liquid was kept under magnetic stirring at room temperature for 24 hours. The reaction product was washed and finally dried at $100{ }^{\circ} \mathrm{C}$ for 12 hours. The graphene oxide nanosheets (GONS) with the lateral dimension of $0.5-5 \mu \mathrm{m}$ and the thickness of $0.8-1.2 \mathrm{~nm}$ were purchased from Nanjing XFNANO Materials Tech Co., Ltd.

\subsection{Characterization of LDHs}

A Bruker D8 Advance diffractometer was used to obtain the dry powder X-ray diffraction (XRD) pattern 
in reflection mode ( $\mathrm{Cu} \mathrm{K} \alpha$ radiation, $\lambda=1.54 \AA$ ) over a $2 \theta$ range of $3^{\circ}-70^{\circ}$. TEM and SEM were utilized to ascertain the morphology and size of LDHs. The TEM images of LDHs were obtained using a JEM 2010 microscope at an accelerating voltage of $120 \mathrm{kV}$. The SEM images were obtained by a cold field emission SEM (HITACHI, SU8220). LDH samples were ultrasonically dispersed in water; then the aqueous suspension was dropped on carbon films for TEM or fresh silicon for SEM, and dried at $80^{\circ} \mathrm{C}$ for 10 hours in air. Quadrasorb SI (Quantachrome) was used to obtain $\mathrm{N}_{2}$ isotherms of LDHs at $-196^{\circ} \mathrm{C}$. The specific surface area (SSA) was calculated by Brunauer-Emmett-Teller (BET) method. The thermogravimetric analysis (TGA) of LDH nanosheets was conducted by NETZSCH STA $449 \mathrm{~F} 3$ under nitrogen from 30 to $800{ }^{\circ} \mathrm{C}$ at a heating rate of $10^{\circ} \mathrm{C} \cdot \mathrm{min}^{-1}$.

\subsection{Tribological experiments and evaluation}

The base grease Mobil MP (150 cSt at $40^{\circ} \mathrm{C}$, drop point $180{ }^{\circ} \mathrm{C}$ ), which mainly consisted of lithium hydroxystearate, was selected. The above as-prepared powder samples were evenly dispersed to the base grease in a ratio of $1 \mathrm{wt} \%$ by a grinder, as shown in Fig. 1, for the following tribological test. A ball-on-disk SRV4 tribometer (Optimal, Germany) in reciprocating mode was used to conduct tribological tests at $80{ }^{\circ} \mathrm{C}$ with the applied load of $150 \mathrm{~N}$ (which corresponded to a maximum Hertz contact pressure of $2.47 \mathrm{GPa}$ ), stroke of $2 \mathrm{~mm}$ and reciprocating frequency of $50 \mathrm{~Hz}$ for 1 hour (a total sliding distance of $720 \mathrm{~m}$ ). The room

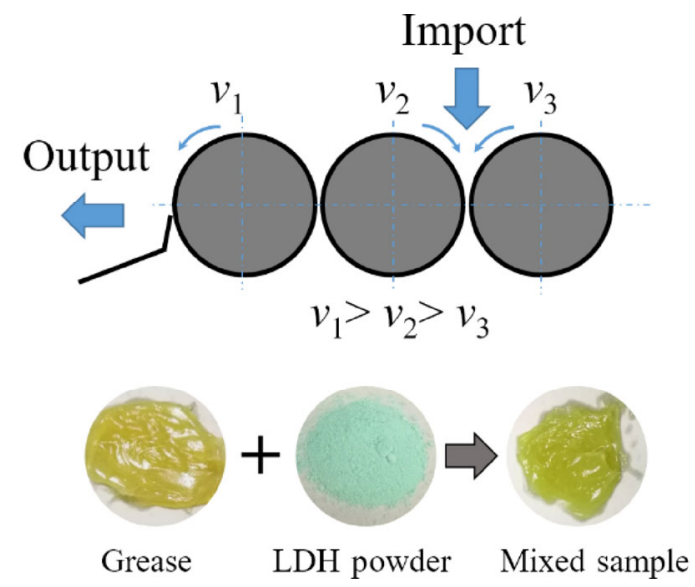

Fig. 1 Schematic diagram of grinder and the dispersion effect of $\mathrm{LDH}$ powder in grease. humidity was $30 \% \mathrm{RH}$. A running-in process at $50 \mathrm{~N}$ was employed for 30 seconds in the beginning of each test. Both balls $(10 \mathrm{~mm}$ in diameter, surface roughness Sa $8.4 \mathrm{~nm}$ ) and disks (polished, surface roughness Sa $7.6 \mathrm{~nm}$ ) for tribological test were made of AISI 52100 bearing steel and all ultrasonically washed with petroleum ether, acetone and ethanol, respectively. The sliding solid surfaces after friction test were examined by a 3D optical surface profiler (Zygo Nexview), SEM (HITACHI, SU8220) and analyzed by energy dispersive X-ray spectrometer (Bruker, QUANTAX FlatQUAD). The differential scanning calorimetry (DSC) of grease samples was conducted by NETZSCH STA 449F3 in air from 50 to $500{ }^{\circ} \mathrm{C}$ at a heating rate of $5^{\circ} \mathrm{C} \cdot \mathrm{min}^{-1}$.

\section{Results and discussion}

Since the metal ions of LDHs in the laminate with positive charge were replaceable, the tribological properties of LDHs with different chemical composition can be explored to provide a guidance for the selection of such materials. Here, four submicron LDH samples were prepared using the same coprecipitation method but the types of divalent metal cations were different, including zinc aluminum ( $\mathrm{ZnAl})$, magnesium aluminum (MgAl), nickel aluminum (NiAl), and cobalt aluminum (CoAl). The morphology and crystal structure of these LDH samples can be determined by their SEM images and XRD patterns shown in Figs. 2(a) and 2(b). From the SEM image in Fig. 2(a), it can be found that all these samples exhibited a two-dimensional sheet morphology, and the lateral dimension was in the range of 50 to $140 \mathrm{~nm}$ by measurement. Besides, the XRD analysis was performed on all powder samples, and each pattern is shown in Fig. 2(b). It can be found that the characteristic peaks of these samples were quite similar and all corresponded to the typically hexagonal phase of LDH crystal structure. Among them, the peaks of $\mathrm{ZnAl-LDH}$ were the sharpest and thus its crystal structure was considered as the most complete one. After these LDHs were dispersed using the same method, the tribological properties of these samples were evaluated and the relevant results were recorded. The COF curves with time of five grease samples are shown in Figs. 2(c) and 2(d). With the addition of LDH samples with 

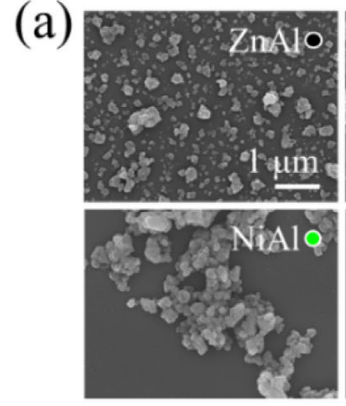

(c)

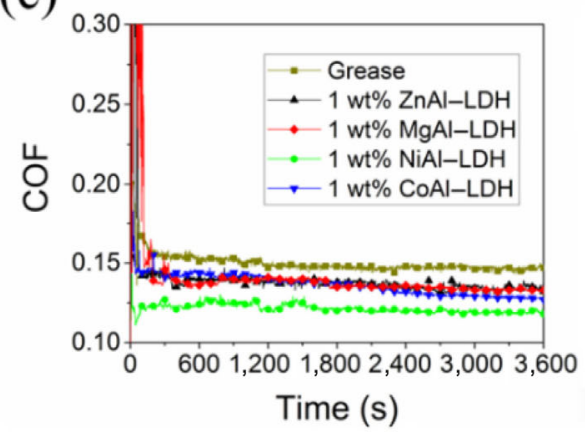

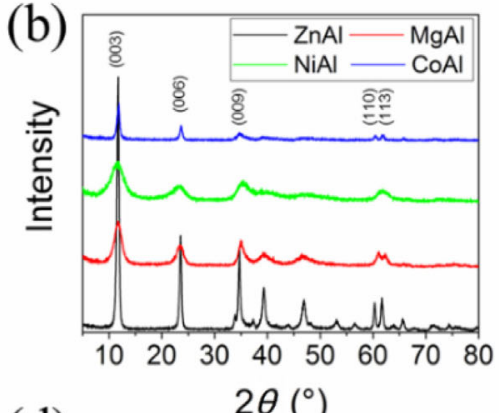

(d)

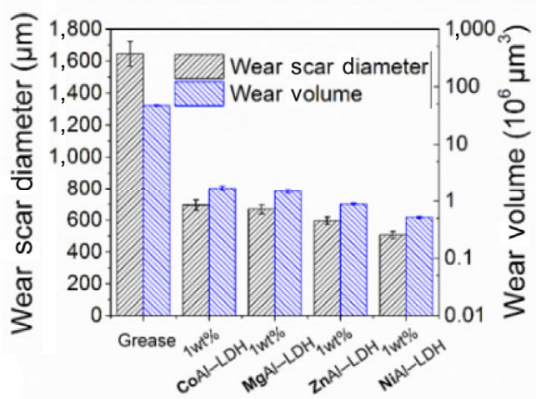

Fig. 2 (a) SEM images and (b) XRD patterns of ZnAl-, MgAl-, NiAl- and CoAl-LDHs. (c) Friction coefficient and (d) wear condition of base grease and those with $1 \mathrm{wt} \% \mathrm{LDHs}$.

different chemical compositions to the base grease, the COF got slightly lower than that of the base grease in Fig. 2(c). Among them, the lowest COF value on average was the NiAl-LDH sample (about 0.125), which was about $16.7 \%$ lower than the average $\mathrm{COF}$ of the base grease (0.151). Besides, other three kinds of LDHs with different chemical compositions (ZnAl-, $\mathrm{MgAl}-$ and CoAl-LDHs) showed a certain effect on the reduction of friction but no big difference as compared with each other. Subsequently, the wear scar of ball after friction test was cleaned and measured. The statistical result in Fig. 2(d) indicated that the anti-wear properties of the grease with these four LDH samples were obviously improved as compared with that of base grease. As compared with each other, it was found that those properties of wear resistance were quite similar. Among them, the dimension of the wear scar tested with the additive of NiAl-LDH was the smallest one, which was only about $30 \%$ of that tested by the base grease. Moreover, the wear volume of ball was only about $1 \%$ of that tested by the base grease. It can be summarized that the simple adjustment of chemical composition of LDHs as lubricant additives in base grease showed no big difference on the tribological performance.
In addition, varieties LDHs with quite different morphology but similar chemical composition can be obtained by adjusting the reaction condition in synthesis process, thus the influence of topographical variations of LDHs as lubricant additives on the tribological performance deserves to be further investigated. According to the previous results, various divalent metal ions of additives showed nearly no big difference on the tribological performance in this lubrication system. Meanwhile, it is generally believed that the morphology of MgAl-LDHs is much easily controllable and prepared, as compared to the other compositions of LDHs.

Here, the morphology and crystal structure of three different MgAl-LDH samples can be determined by their SEM images and XRD patterns shown in Fig. 3. The "plate-like" LDHs shown in Fig. 3(a) showed a remarkable two-dimensional morphology; the LDH platelets in Fig. 3(b) were clustered together to show the "flower-like" morphology and their lateral dimension was significantly large; the size of LDHs in Fig. 3(c) was relatively small and the (110) crystal plane failed to sufficiently grow, so that the "spherical" sample exhibited a zero-dimensional morphology. The XRD patterns of three powder samples in Fig. 3(d) all showed 

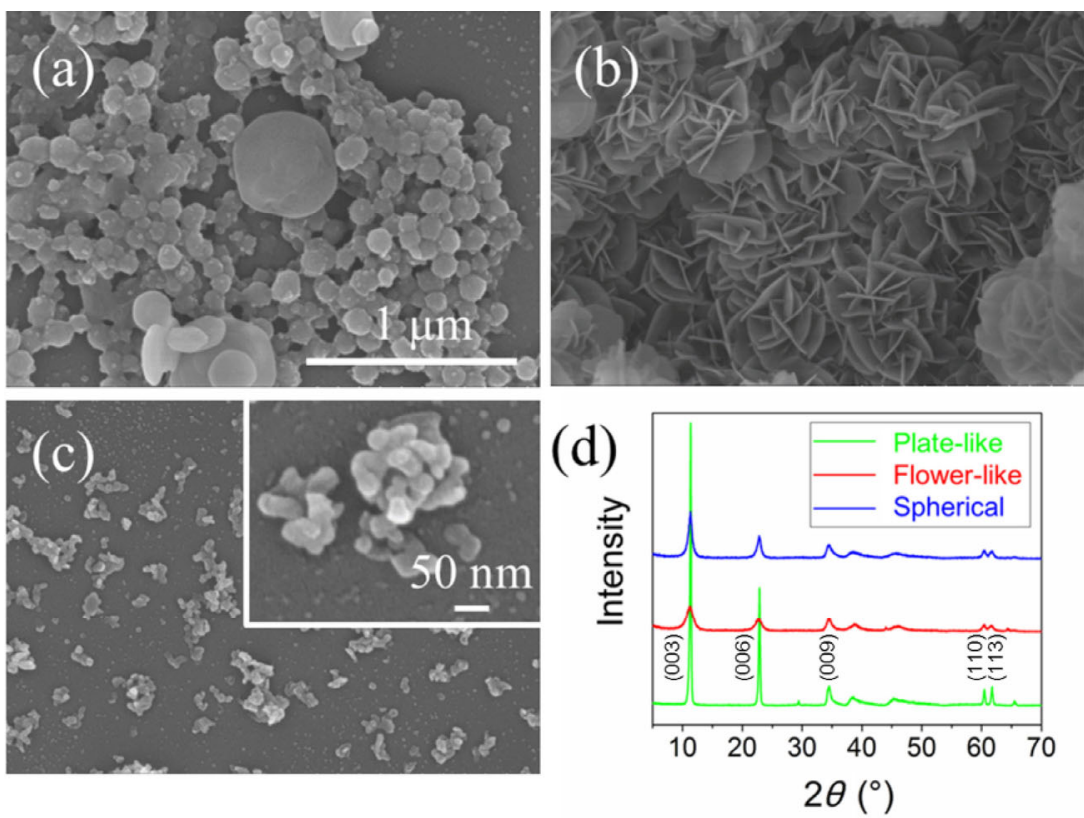

Fig. 3 SEM images of MgAl-LDHs with (a) plate-like, (b) flower-like, and (c) spherical morphology; (d) XRD patterns of these LDHs.

characteristic structure of LDHs with hexagonal phase, while the sharpest characteristic peaks of the "plate-like" LDH, obtained with hydrothermal process, indicated its best crystallinity.

Three MgAl-LDHs with flower-like, spherical and plate-like morphology were dispersed in base grease in a ratio of $1 \mathrm{wt} \%$ for friction test. The friction coefficient (COF) curves with time of four lubricant samples was shown in Fig. 4(a). With the addition of LDHs, the friction coefficient generally got lower than that of base grease. Among these three LDH samples, the lowest average friction coefficient obtained with flower-like sample was about 0.125 and kept quite stable; the COF of spherical sample maintained at a low level after short running-in period; the COF of plate-like sample however took relatively longer running-in time to stabilize at low value. In terms of anti-wear properties, the diameter and surface topography of wear scars after test were analyzed and compared in Fig. 4(b). The wear resistance of sliding solid surfaces, lubricated with the addition of LDHs in grease, all got obviously improved to varying degrees as compared with that lubricated by base grease. Among them, the flower-like LDH sample showed the greatest improvement in anti-wear performance, where the wear scar diameter of the ball was about $27 \%$ and the wear volume was only about $0.2 \%$ of that lubricated by base grease.

Here, the lubricant mechanism of LDH additives with different morphology is investigated. Considering
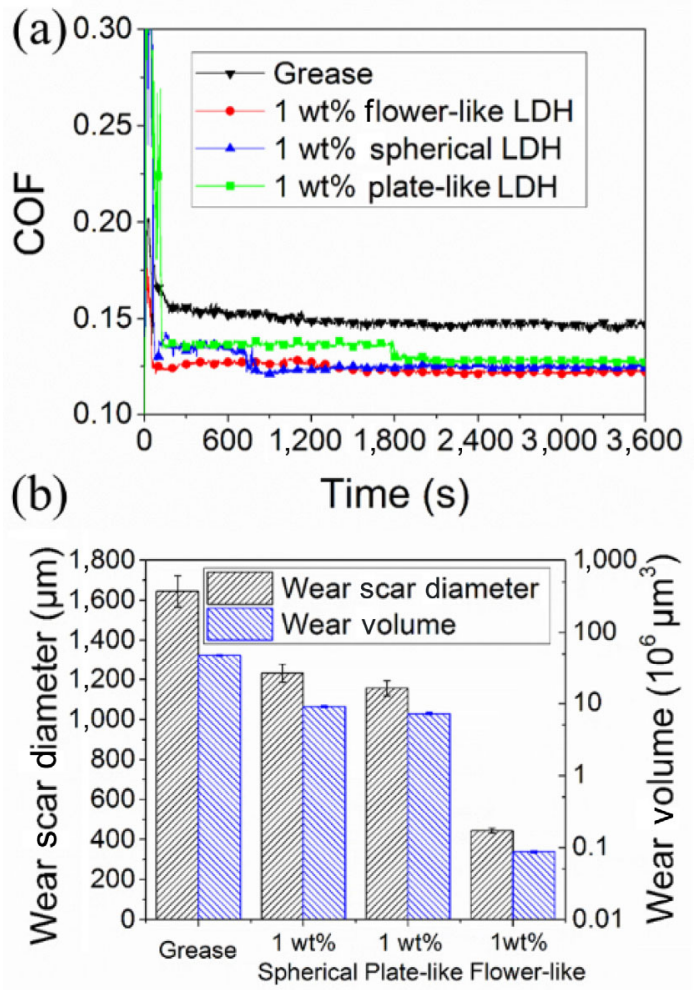

Fig. 4 (a) Friction coefficient and (b) wear condition of $1 \mathrm{wt} \%$ MgAl-LDHs with different morphology (flower-like, spherical, and plate-like) in base grease. 
that the chemical composition of these LDHs was almost the same, the specific surface area (SSA) of them was calculated, according to the $\mathrm{N}_{2}$ isotherms in Fig. 5(a), and compared to determine their difference in microstructure. The measurement results indicated the highest SSA $\left(139 \mathrm{~m}^{2} / \mathrm{g}\right)$ of the LDH with flowerlike microstructure but the relatively low value of spherical $\left(99 \mathrm{~m}^{2} / \mathrm{g}\right)$ and plate-like $\left(16 \mathrm{~m}^{2} / \mathrm{g}\right)$ sample. Through observing the TEM image of flower-like LDH in Fig. 5(b), ultrathin laminates and loose microstructures were further confirmed directly. Therefore, it is reasonable to indicate that the LDH sample with both higher SSA and larger lateral dimension will take a better lubricating effect in base grease because of their much more rapid and efficient combination with the substrate to protect the sliding surfaces from severe wear condition.

In order to investigate the lubricating effects of LDHs as lubricant additives on the contact area during the sliding process, the element distribution in wear track was detected by SEM after friction test. As shown in Fig. 6, the morphology and element distribution of the

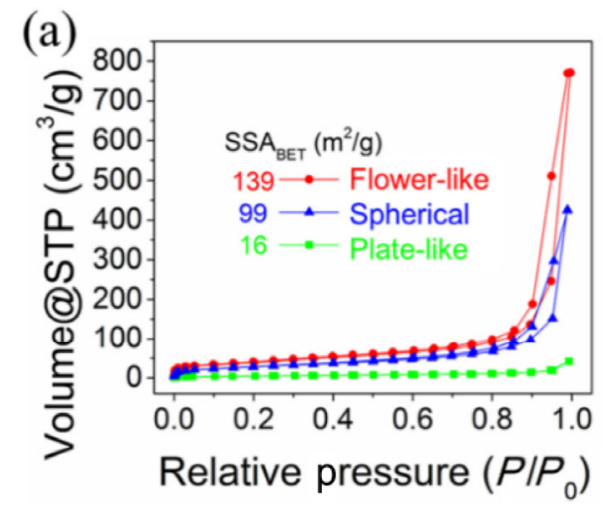

(b)

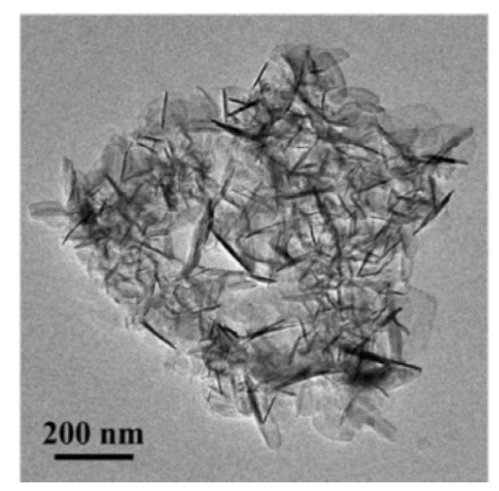

Fig. 5 (a) $\mathrm{N}_{2}$ isotherms of LDHs with different morphology at standard temperature and pressure; (b) TEM image of flower-like LDH sample.
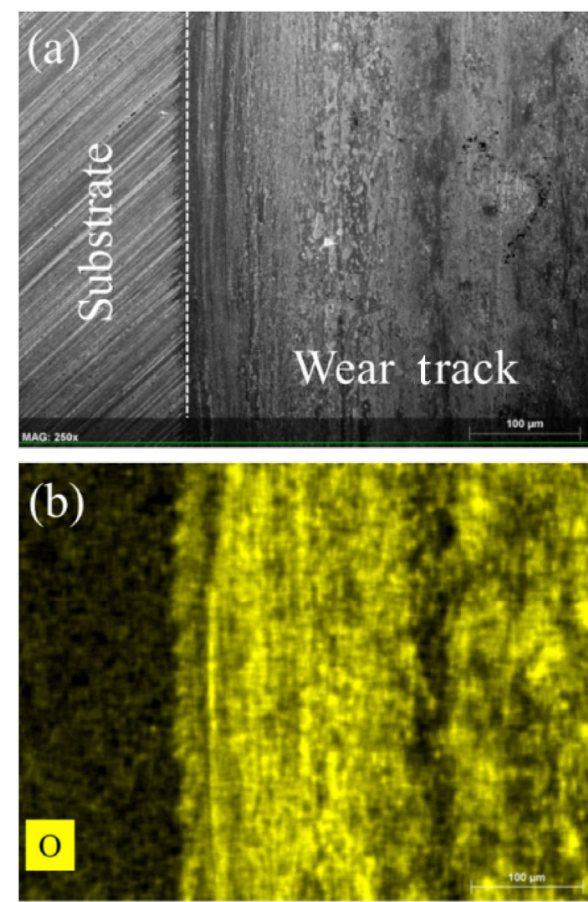

Fig. 6 (a) SEM image and (b) oxygen distribution of wear track lubricated by base grease.

wear track lubricated by base grease were observed at first. The result showed that the oxygen content in the wear track was significantly higher than that of the substrate after friction test, thus it can be considered that significant oxidation occurred on the contact surfaces due to violent collision between asperities of solid surfaces.

After that, the element distribution of wear scar lubricated by $1 \mathrm{wt} \%$ flower-like MgAl-LDHs was analyzed and is shown in Fig. 7 to demonstrate the lubricating effect of LDHs on the sliding surfaces. It can be easily found that the elements magnesium and aluminum were concentrated in the transition region between the wear scar and steel substrate, which was quite similar to the distribution of Hertz contact pressure. In addition, the oxidation degree of sliding solid surfaces was obviously decreased in the central region, where the lubricating film thickness was minimum [26]. It was indicated that the violent rubbing process constantly renewed sliding solid surfaces in the central region, which were so difficult to fully involve in the tribochemical reaction. Meanwhile, the LDH nanosheets as additives were able to avoid direct collision of asperities in the sliding process. Thus, a relatively complete tribofilm, rich in magnesium and 

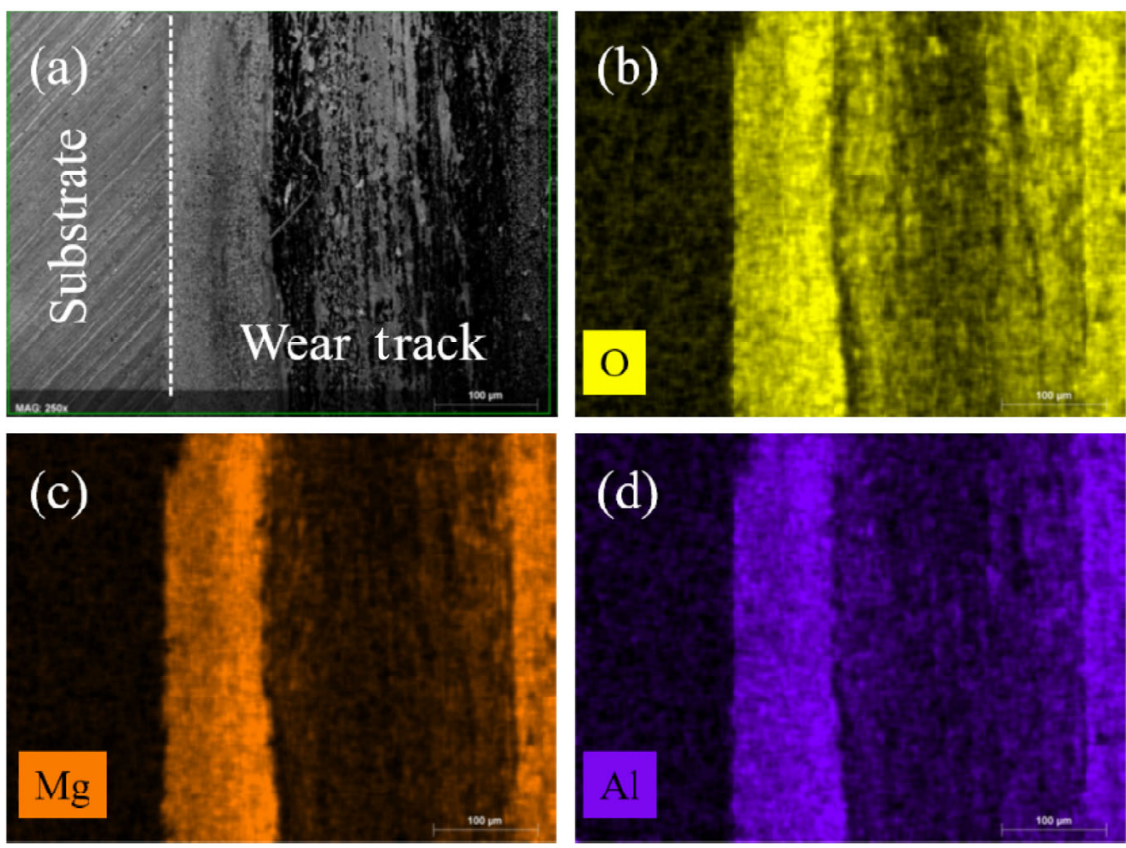

Fig. 7 (a) SEM image and (b) oxygen, (c) magnesium and (d) aluminum distribution of wear track lubricated by 1 wt $\%$ flower-like $\mathrm{LDH}$ in base grease.

aluminum elements, was mainly formed on the area of sliding solid surfaces with relatively low contact pressure. In addition, considering the importance of thermostability and oxidation resistance of grease for practical applications, the thermogravimetric analysis (TGA) of flower-like LDH nanosheets and differential scanning calorimetry (DSC) of as-prepared grease sample were conducted. As shown in Fig. S1 in the Electronic Supplementary Material (ESM), the weight loss in the first region $\left(30-231^{\circ} \mathrm{C}\right)$ can be attributed to the loss of water molecules adsorbed on the surface and among the interlayer of laminates, which will not significantly influence their crystal structure. However, the hydroxyl among the interlayer will be gradually decomposed in the second region $\left(231-800{ }^{\circ} \mathrm{C}\right)$ of weight loss and then the layered structure will be completely destroyed [20]. As the dehydration temperature of $182{ }^{\circ} \mathrm{C}$ is relatively higher than the drop point $\left(180^{\circ} \mathrm{C}\right)$ of base grease, the grease sample with $\mathrm{LDH}$ additives is considered to be stably applied in the practical condition, where the applicable temperature is commonly $20-30{ }^{\circ} \mathrm{C}$ below the drop point. The differential scanning calorimetry (DSC) of base grease and as-prepared grease sample with $1 \mathrm{wt} \%$ flower-like LDH was conducted in air and the result in Fig. S2 in the ESM shows that the exothermic peaks of these two grease samples are quite similar during heating process. It indicates that the oxidation resistance of grease will not be significantly influenced with $\mathrm{LDH}$ additives. Moreover, in order to compare with the commonly used two-dimensional additives, $1 \mathrm{wt} \%$ graphene oxide nanosheets (GONS) with the lateral dimension of $0.5-5 \mu \mathrm{m}$ and the thickness of $0.8-1.2 \mathrm{~nm}$, were dispersed into the base grease. Then, the friction test with $1 \mathrm{wt} \%$ GONS sample was conducted under the same applied conditions. As shown in Fig. S3 in the ESM, both COF value and wear condition were recorded, which demonstrated that GONS exhibited good tribological properties as lubricant additives. However, the additive sample with best friction performance and wear resistance is the flower-like LDH, whose COF value was relatively low and its wear volume was only $20.96 \%$ of that lubricated by $1 \mathrm{wt} \%$ GONS sample. Thus, as a short conclusion, the tribological properties can be improved with MgAl$\mathrm{LDH}$ additives with various morphologies in base grease, and the flower-like sample with high SSA and large lateral dimension performed best.

The high magnification SEM images of wear tracks after friction tests were obtained and shown in Figs. 8(a) and $8(\mathrm{~b})$ to further compare the microscopic topography in the sliding area with the addition of LDH in base 

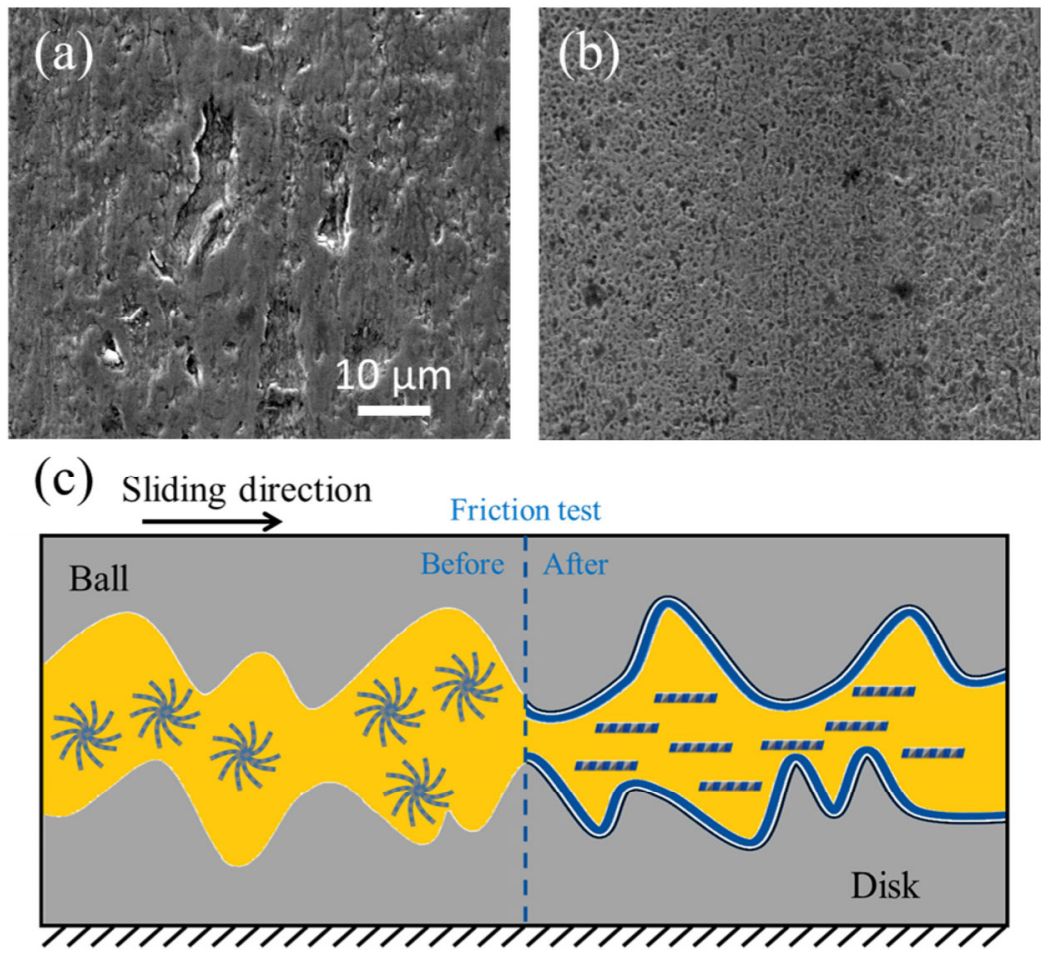

Fig. 8 High magnification SEM images of wear track lubricated by (a) base grease and (b) 1 wt $\%$ flower-like $\mathrm{MgAl}-\mathrm{LDH}$ in base grease. (c) Schematic illustration of the proposed lubrication model with flower-like LDH additives in base grease.

grease. Since the friction process usually occurred in the air and the temperature in the contact area increased rapidly, which tended to rapidly oxidize the sliding steel surface and cause obvious adhesive effect. For the wear track lubricated by base grease, a significant adhesive wear can be found in Fig. 8(a), where the plastic deformation caused by the interaction between directly contacting asperities resulted in high friction coefficient and severe wear condition. However, with a small amount of flower-like LDH additives, the microstructure of sliding surfaces in the contact area became quite dense and uniform (see Fig. 8(b)), which weakened the plastic deformation and facilitated reducing the friction coefficient during the rubbing process [21].

Here, it is quite necessary to estimate the film thickness in contact area so as to evaluate the tribological behavior of LDH additives in base grease. According to the Hamrock-Dowson theory, the minimum film thickness can be calculated by the formula $[3,27]$ :

$$
h_{\min }=3.63 \frac{U^{0.68} G^{0.49} R}{W^{0.073}}\left(1-\mathrm{e}^{-0.68 k}\right)
$$

where $U=\eta V / E^{\prime} R, G=\alpha E^{\prime}, W=F / E^{\prime} R^{2}, R$ was the radius of the ball $(5 \mathrm{~mm}), V(\sim 200 \mathrm{~mm} / \mathrm{s})$ was the relative velocity of sliding surface, $E^{\prime}$ was the effective modulus of elasticity (the elastic modulus $E$ of solid surfaces was $206 \mathrm{GPa}$ with the Poisson's ratio $v$ of $0.3), F(150 \mathrm{~N})$ was the normal load, and $k(\sim 1)$ was the ellipticity, $\eta\left(\sim 20 \mathrm{cP}\right.$ at $\left.80{ }^{\circ} \mathrm{C}\right)$ was the shear viscosity of fluid, $\alpha\left(\sim 15 \mathrm{GPa}^{-1}\right)$ [3] was the viscosity-pressure coefficient.

Here, the minimum film thickness was calculated to be $\sim 30 \mathrm{~nm}$, which was much thinner as compared to the dimension of flower-like LDH sample, so that its microstructure was considered to be damaged and exfoliated to nanosheets during the sliding process.

According to all experimental results, it was easily found that the flower-like LDH additives with high SSA and large lateral dimension showed best tribological properties in base grease. As illustrated in Fig. 8(c), the schematic lubrication model was proposed. The remarkable microscopic fold structure was initially destroyed under high contact pressure (up to $2.47 \mathrm{GPa}$ ) during the collision of approaching asperities, and meanwhile a large amount of ultrathin LDH nanosheets 
were generated. To some extent, the probability of direct contact between LDH nanosheets and sliding solid surfaces was highly increased. The ultrathin LDH nanosheets physically prevented direct collision of asperities in the central region of contact area during the violent rubbing process. On the other hand, a relatively dense protective tribofilm with enhanced mechanical property was formed by the occurrence of tribochemical reaction between $\mathrm{LDH}$ additives and sliding solid surfaces, which greatly improved the wear resistance of contact surfaces.

\section{Conclusions}

In this paper, three types of MgAl-LDHs with different topographical features and four kinds of samples with different chemical compositions of divalent cations were prepared. Then, their tribological properties were evaluated and compared. It was found that the variation of morphology, rather than the chemical composition, had great influence on the tribological performance. The flower-like LDH sample with high specific surface area and ultrathin laminates were demonstrated to exhibit the best tribological properties. Under the same experimental conditions, the wear volume was only about $0.2 \%$ of that lubricated by base grease. By observing and analyzing the wear track after friction test, the tribofilm formed with unique microscopic structure and chemical composition derived from LDH additives was conducive to effectively improving tribological properties of the lubrication system.

\section{Author contributions}

Hongdong WANG and Yue WANG conducted the experiments. Hongdong WANG finished the main manuscript. All authors contributed to the analysis and discussion of the data, reviewed the manuscript, and have given approval to the final version of the manuscript.

\section{Acknowledgements}

This work was financially supported by the National Natural Science Foundation of China (Nos. 51905294,
51905027, 51527901, and 51875303), China Postdoc Innovation Talent Support Program (No. BX20180168), and the China Postdoctoral Science Foundation (No. 2019M650654).

Electronic Supplementary Material: Supplementary material is available in the online version of this article at https://doi.org/10.1007/s40544-020-0380-5.

Open Access: This article is licensed under a Creative Commons Attribution 4.0 International License, which permits use, sharing, adaptation, distribution and reproduction in any medium or format, as long as you give appropriate credit to the original author(s) and the source, provide a link to the Creative Commons licence, and indicate if changes were made.

The images or other third party material in this article are included in the article's Creative Commons licence, unless indicated otherwise in a credit line to the material. If material is not included in the article's Creative Commons licence and your intended use is not permitted by statutory regulation or exceeds the permitted use, you will need to obtain permission directly from the copyright holder.

To view a copy of this licence, visit http://creativecommons.org/licenses/by/4.0/.

\section{References}

[1] Persson B N J. Sliding Friction: Physical Principles and Applications. 2nd ed. Heidelberg (UK): Springer, 2000.

[2] Perry S S, Tysoe W T. Frontiers of fundamental tribological research. Tribol Lett 19(3): 151-161 (2005)

[3] Wen S Z, Huang P. Principles of Tribology. Hoboken (USA): John Wiley \& Sons, 2012.

[4] Ye C F, Liu W M, Chen Y X, Yu L G. Room-temperature ionic liquids: a novel versatile lubricant. Chem Commun 2001: 2244-2245 (2001)

[5] Qu J, Luo H M, Chi M F, Ma C, Blau P J, Dai S, Viola M B. Comparison of an oil-miscible ionic liquid and ZDDP as a lubricant anti-wear additive. Tribol Int 71: 88-97 (2014)

[6] Qu J, Barnhill W C, Luo H M, Meyer III H M, Leonard D N, Landauer A K, Kheireddin B, Gao H, Papke B L, Dai S. Synergistic effects between phosphonium-alkylphosphate ionic liquids and Zinc Dialkyldithiophosphate (ZDDP) as lubricant additives. Adv Mater 27(32): 4767-4774 (2015)

[7] Chen Z, Liu X W, Liu Y H, Gunsel S, Luo J B. Ultrathin 
$\mathrm{MoS}_{2}$ nanosheets with superior extreme pressure property as boundary lubricants. Sci Rep 5: 12869 (2015)

[8] Chhowalla M, Amaratunga G A J. Thin films of fullerene-like $\mathrm{MoS}_{2}$ nanoparticles with ultra-low friction and wear. Nature 407(6801): 164-167 (2000)

[9] Njiwa P, Hadj-Aïssa A, Afanasiev P, Geantet C, Bosselet F, Vacher B, Belin M, Le Mogne T, Dassenoy F. Tribological properties of new $\mathrm{MoS}_{2}$ nanoparticles prepared by seedassisted solution technique. Tribol Lett 55(3): 473-481 (2014)

[10] Wu J, Mu L W, Zhu J H, Feng X, Lu X H, Larsson R, Shi Y J. Synthesis of hollow fullerene-like molybdenum disulfide/ reduced graphene oxide nanocomposites with excellent lubricating properties. Carbon 134: 423-430 (2018)

[11] Wang W, Xie G X, Luo J B. Black phosphorus as a new lubricant. Friction 6(1): 116-142 (2018)

[12] Wang W, Xie G X, Luo J B. Superlubricity of black phosphorus as lubricant additive. ACS Appl Mater Interfaces 10(49): 43203-43210 (2018)

[13] Berman D, Erdemir A, Sumant A V. Graphene: a new emerging lubricant. Mater Today 17(1): 31-42 (2014)

[14] Berman D, Deshmukh S A, Sankaranarayanan S K R S, Erdemir A, Sumant A V. Macroscale superlubricity enabled by graphene nanoscroll formation. Science 348(6239): 11181122 (2015)

[15] Kawai S, Benassi A, Gnecco E, Sode H, Pawlak R, Feng X L, Müllen K, Passerone D, Pignedoli C A, Ruffieux P, et al. Superlubricity of graphene nanoribbons on gold surfaces. Science 351(6276): 957-961 (2016)

[16] Kinoshita H, Nishina Y, Alias A A, Fujii M. Tribological properties of monolayer graphene oxide sheets as water-based lubricant additives. Carbon 66: 720-723 (2014)

[17] Zhang Z N, Liu J, Wu T H, Xie Y B. Effect of carbon nanotubes on friction and wear of a piston ring and cylinder liner system under dry and lubricated conditions. Friction 5(2): 147-154 (2017)

[18] Wang X B, Bai Z M, Zhao D, Zhao F Y. Friction behavior

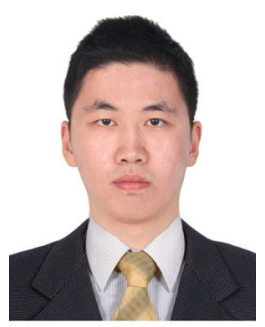

Hongdong WANG. He got his Ph.D. degree from State Key Laboratory of Tribology at Tsinghua University in 2018 and now is a postdoctor at of $\mathrm{Mg}-\mathrm{Al}-\mathrm{CO}_{3}$ layered double hydroxide prepared by magnesite. Appl Surf Sci 277: 134-138 (2013)

[19] Wang H D, Liu Y H, Guo F M, Sheng H P, Xia K L, Liu W R, Wen J G, Shi Y J, Erdemir A, Luo J B. Catalytically active oil-based lubricant additives enabled by calcining Ni-Al layered double hydroxides. J Phys Chem Lett 11: 113-120 (2020)

[20] Wang H D, Liu Y H, Chen Z, Wu B B, Xu S L, Luo J B. Layered double hydroxide nanoplatelets with excellent tribological properties under high contact pressure as waterbased lubricant additives. Sci Rep 6: 22748 (2016)

[21] Wang H D, Liu Y H, Liu W R, Wang R, Wen J G, Sheng H P, Peng J F, Erdemir A, Luo J B. Tribological behavior of NiAl-Layered double hydroxide nanoplatelets as oil-based lubricant additives. ACS Appl Mater Interfaces 9(36): 30891-30899 (2017)

[22] Wang H D, Liu Y H, Liu W R, Liu Y M, Wang K P, Li J J, Ma T B, Eryilmaz O L, Shi Y J, Erdemir A, et al. Superlubricity of polyalkylene glycol aqueous solutions enabled by ultrathin layered double hydroxide nanosheets. ACS Appl Mater Interfaces 11(22): 20249-20256 (2019)

[23] Malak-Polaczyk A, Vix-Guterl C, Frackowiak E. Carbon/ Layered Double Hydroxide (LDH) composites for supercapacitor application. Energy Fuels 24(6): 3346-3351 (2010)

[24] Ma W, Ma R Z, Wang C X, Liang J B, Liu X H, Zhou K C, Sasaki T. A superlattice of alternately stacked Ni-Fe hydroxide nanosheets and graphene for efficient splitting of water. ACS Nano 9(2): 1977-1984 (2015)

[25] O'Leary S, O'Hare D, Seeley G. Delamination of layered double hydroxides in polar monomers: new LDH-acrylate nanocomposites. Chem Commun (14): 1506-1507 (2002)

[26] Li G, Zhang C H, Luo J B, Liu S H, Xie G X, Lu X C. Film-forming characteristics of grease in point contact under swaying motions. Tribol Lett 35(1): 57-65 (2009)

[27] Dowson D, Jin Z M. Metal-on-metal hip joint tribology. Proc Inst Mech Eng HJ Eng Med 220(2): 107-118 (2006)

Tsinghua University. His research topics focus on the water-based superlubricity and the application of two dimensional nanomaterials in tribology. 


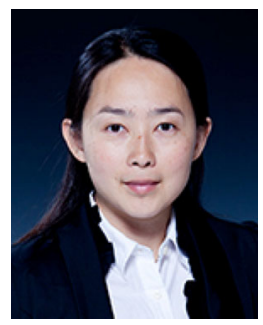

Yuhong LIU. She received her Ph.D. degree in Chinese Academy of Sciences Key Laboratory of Molecular Nanostructure \& Nanotechnology Institute of Chemistry, CAS, Beijing, China, in 2005. She is

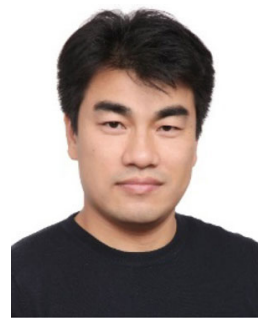

Qiang WANG. He received the BEng degree (2003) and MEng degree (2005) from Harbin Institute of Technology in China, and the Ph.D. degree (2009) from POSTECH in South Korea. During 2009-2011, he worked as Research Fellow in the Institute of Chemical and Engineering Sciences under Agency for Science, Technology and Research

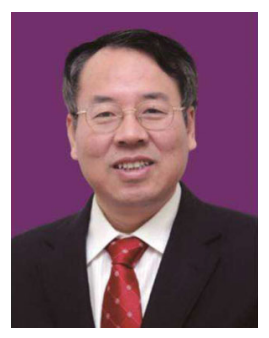

Jianbin LUO. He received his BEng degree from Northeastern University in 1982, and MEng degree from Xi'an University of Architecture and Technology in 1988. In 1994, he received his Ph.D. degree from Tsinghua University and then joined the faculty of Tsinghua University. Prof. Luo is an academician of the Chinese Academy of Sciences and a Yangtze River Scholar Distinguished Professor of an associate professor at the State Key Laboratory of Tribology of Tsinghua University, China, from 2005. Her research areas cover nanotribology, nanostructure, nanotechnology of surface and interface, chemicalmechanical planarization, and water-based lubrication.

(A*STAR), Singapore. During 2011-2012, he worked as postdoctoral associate in the Department of Chemistry, University of Oxford in United Kingdom. Since 2012, he has been a full professor position in the College of Environmental Science and Engineering, Beijing Forestry University. His research interests are environmental functional nanomaterials, particularly in $\mathrm{CO}_{2}$ capture and utilization, and catalytic removal of VOCs and $\mathrm{NO}_{x}$, etc.

Tsinghua University, Beijing, China. He was awarded the STLE International Award (2013), the Chinese National Technology Progress Prize (2008), the Chinese National Natural Science Prize (2001), and the Chinese National Invention Prize (1996). Prof. Luo has been engaged in the research of thin film lubrication and tribology in nanomanufacturing. He was invited as a keynote or plenary speaker for 20 times on the international conferences. 